\title{
Alteridade humana e contingência no Reino
}

\section{Human alterity and contingency in the Kingdom}

\author{
La alteridad humana y la contingencia en el Reino
}

\section{Odirlei Arcangelo Lovo}

\begin{abstract}
RESUMO
A pessoa ególatra torna a contingência no reino em obstáculo à vida humana, recusa-se a administrar as necessidades, as possibilidades e os subsídios que se tem à disposição. $\mathrm{O}$ ególatra se torna empecilho à graça de Deus, nega o reino de Deus que acontece sob o agir/ administrar humano. É preciso pontuar que a realidade e vivência humana precisa se atentar em observar que não é o que se tem, mas quantos vivem bem com o que se tem, sem que para isso, outros tenham vivido, vivam, ou venham a viver mal. É necessário se indagar: o agir humano acontece em perspectiva da edificação de todos os seres humano e do ser humano como um todo? A proposta é narrar o ser humano administrador e cocriador da obra de Deus, tendo por base os documentos da Doutrina Social da Igreja Católica, bem como, os documentos que elucidam a vida e vivência da família "moral familiar". O agir de cada pessoa deve refletir o amor de Deus, isso significa que o ser humano é, em Cristo, a criatura à qual Deus confia sua obra, para que possa administrá-la e cocriá-la.

Palavras-chave: Ação humana; ação de Deus; esponsalidade; essência administrativa; cocriação.
\end{abstract}

\begin{abstract}
The egocentric person makes contingency in the kingdom an obstacle to human life, refuses to manage the needs, possibilities and subsidies that are available. The egolater becomes an obstacle to the grace of God, denies the kingdom of God that takes place under human action / administration. It is necessary to point out that reality and human experience must pay attention to observing that it is not what we have, but how many live well with what we have, without that, others have lived, live, or come to live badly. It is necessary to ask: does human action take place in the perspective of the edification of all human beings and of human beings as a whole? The proposal is to narrate the human being administrator and co-creator of the work of God, based on the documents of the Social Doctrine of the Catholic Church, as well as, the documents that elucidate the life and experience of the family "family morals". The action of each person must reflect the love of God, this means that the human being is, in Christ, the creature to whom God entrusts his work, so that he can manage and co-create it.
\end{abstract}

Keywords: Human action; God's action; spousality; administrative essence; co-creation.

\begin{abstract}
RESUMEN
La persona egocéntrica hace de la contingencia en el reino un obstáculo para la vida humana, se niega a gestionar las necesidades, posibilidades y subsidios disponibles. El ego luego se convierte en un obstáculo para la gracia de Dios, niega el reino de Dios que tiene lugar bajo la acción / administración humana. Es necesario señalar que la realidad y la experiencia humana deben prestar atención a observar que no es lo que tenemos, sino cuántos vivimos bien con lo que tenemos, sin eso, otros han vivido, viven o vienen a vivir mal. Es necesario preguntarse: ¿la acción humana tiene lugar en la perspectiva de la edificación de todos los seres humanos y del ser humano en su conjunto? La propuesta es narrar al ser humano administrador y cocreador de la obra de Dios, a partir de los documentos de la Doctrina
\end{abstract}


Social de la Iglesia Católica, así como, los documentos que dilucidan la vida y experiencia de la "moral familiar" de la familia. La acción de cada persona debe reflejar el amor de Dios, esto significa que el ser humano es, en Cristo, la criatura a quien Dios confía su obra, para que la pueda gestionar y co-crear.

Palabras clave: Accion humana; la acción de Dios; responsabilidad; esencia administrativa; co-creación.

\section{Introdução}

A alteridade humana não se desenvolve sob o ambiente de individualismo, soberba e egolatria, males que atingem a pessoa e a própria humanidade. Como falar de um Reino em desenvolvimento, quando é a soberba, a egolatria e o individualismo que se agiganta? O desejo é o de edificar o Reino de Deus, portanto, é a pessoa que se há de salvar e oportunizar o desenvolvimento e a consciência de ser o administrador e cocriador do Reino de Deus. O agir humano é fonte de amor e esperança, à medida que se edifica à imagem e semelhança de Deus.

O Cristo é a criatura ungida edificada no búmus da terra, para ser o búmus na criação de Deus, o ser humano quando se edifica em Cristo reconhece que tem um Pai, reconhece que toda vida humana é proveniente do amor de Deus. Neste sentido, o Dom dos Dons - a Essência Administrativa, que é práxis, se torna o elo santificante das pessoas, e cada um pode contribuir de forma eficiente na cocriação da obra de Deus.

Há a egolatria ${ }^{1}$ assola a vida humana, é possível apontar que a negligência à vida, pode acontecer, inclusive, quando se pensa a parentalidade universo familiar doméstico, como razão para se explorar, predatoriamente, a obra de Deus, em benefícios desse que é um projeto pessoa-parental, e não o projeto do Reino de Deus. A parentalidade é a unidade primeira da humanidade, é projeto de Deus à medida que em um gesto fraterno se administra o reino onde se forma a família humana, o povo de Deus.

Este artigo se estrutura na afirmativa, na associação e na inter-relação, metodológica, versando o limiar da Teologia e da Administração. Fazer, segundo a vontade de Deus - esponsalidade ${ }^{2}$, significa administrar a criação e,

\footnotetext{
1 A Egolatria é atitude que torna a si mesmo o absoluto. Há o intuito de fomentar que a egolatria é tão prejudicial quanto a idolatria, nos dois extremos há a visão distorcida da realidade do Reino de Deus.

2 Se deseja apontar com a palavra "Esponsalidade" algo mais forte que o termo "Aliança", pontua-se que Deus se doa constantemente à relação com todo ser humano, e mesmo que o ser humano cause danos à aliança do povo de Deus, a humanidade não poderá romper a Esponsalidade do Criador à sua criatura. Neste sentido, há no íntimo de cada pessoa a dignidade humana, o ser criado à imagem e semelhança de Deus, onde "semelhança de Deus significa, em primeiro lugar, a relação de Deus para com a pessoa e, somente então, a partir disso a relação da pessoa para com Deus" (MOLTMANN, 1993 , p. 318).
} 
por isso, há práxis teológica e, à medida que se faz teologia, compreende-se como administrar a Criação e, neste sentido, subentende-se que "a vida que Deus oferece ao homem, é um dom, pelo qual Deus participa algo de Si mesmo à sua criatura" ( $\left.\mathrm{EV}^{3} 34\right)$.

O ser humano sempre se des-envolve, mediante a essência administrativa e se torna ato administrativo de Deus na criação. Enseja-se que a esperança é constitutiva da ação necessária em perspectiva do reino esperançado, é preciso compreender que "a interpretação correta do conceito de ser humano como senhor do universo é entendê-lo no sentido de administrador responsável" (LS $\left.{ }^{4} 116\right)$.

Elucida-se questões que estão relacionadas ao ser humano, vertendo-se a compreendê-lo como administrador da obra de Deus. Mediante os procedimentos metodológicos, onde se narra o ser humano como o administrador e cocriador da obra de Deus, conduziu-se às possibilidades, às interpretações e às informações, na afirmativa que "uma narrativa é composta por uma sequência singular de eventos, estados mentais, ocorrências envolvendo seres humanos como personagens ou autores" (BRUNER, 2002, p. 46).

A narrativa tem por finalidade explorar, aprofundar e dar respostas às particularidades, onde a realidade não pode, ou não deve ser quantificada, particularizando ainda que, "Uma verdadeira pesquisa narrativa é um processo dinâmico de viver e contar histórias, e reviver e recontar histórias" (CLANDININ; CONELLY, 2011, p. 18).

Para explorar o universo dos significados, das aspirações, das crenças, dos valores e práxis humana, utilizou-se, para a narrativa, dois núcleos fundamentais de dados, textos e informações, a saber: os documentos que constituem a (DSI) - Doutrina Social da Igreja; e os documentos que elucidam o projeto, a vivência e a dinâmica familiar, segundo a Igreja Católica. O uso desses dois núcleos tem por base, sua universalidade, isto é, são documentos que se destinam a toda a humanidade, diante dos dons de cada pessoa.

\section{A egolatria e a contingência do reino}

O individualismo, a egolatria e a soberba condicionam a pessoa a isolar-se, e impossibilitam a alteridade humana. Fala-se da negligência ao próximo, mediante a exploração predatória da criação. A contingência no reino torna-se um obstáculo à vida e vivência humanas, mesmo não havendo dúvida de que a criação produz o suficiente, mas a avareza contingência a participação.

\footnotetext{
JOÃO PAULO II. Evangelium vitae, 1995.

${ }^{4}$ FRANCISCO, Laudato Si', 2015.
} 
É possível observar que há estruturas governamentais estabelecem formas para o desenvolvimento da avareza, da posse e do poder, e isso seduz como fonte de prosperidade egolátrica, realizando-se na obsessão e no consumismo. A ganância e a soberba são a nova serpente, que transforma as aparências e vontades em propósitos de morte; se é os deuses do nada, em que a egolatria é o elemento necessário para discernir e fazer com que se possa dispor do que há de proibido em cada fruto.

É desejo dos indivíduos que se entregam à descartabilidade, ao consumismo que fomenta a cobiça dos indivíduos desenfreados pela posse para além das possibilidades, acometidos pela promessa de que "serão como Deus!" (Gênesis 3,5). O reino de Deus é, então, transformado no Estado da abastança pecaminosa, dos eleitos, dos privilegiados, de todos aqueles que colocam 'deus' como um mordomo, que está à disposição para servi-los, utilizando-se dos serviços de quem não é desejado por 'deus'.

A criação é o ato amoroso de Deus para a edificação do Reino, a vivência humana é o caminho para esse acontecimento, por isso se está em uma criação em desenvolvimento, contingente e necessitada de administradores e cocriadores em esponsalidade com o Criador. "Deus primeiro se decide pelo Reino e então pela criação. É por isso que o Reino determina a criação, e a criação é a promessa real do Reino" (MOLTMANN, 1993, p. 128).

É preciso inspirar-se em 'Abraão', abandonar a idolatria, sem adentrar a egolatria, ter uma atitude paterna "pai de uma grande nação" (Gênesis 17,4), que cuida, guarda e cultiva o patrimônio comum dos que são filhos de Deus. Não se pode compreender o lar, como reflexo do Criador, quando a parentalidade se fecha em si mesma, pois a parentalidade é reflexo do amor divino, quando se abre em um laço de amor para toda a família humana.

Abraão compreende-se filho, ao se descobrir cocriador e administrador, o Pai de uma grande nação, ao sentir-se amado por Deus, ao corresponder-se no mistério de esponsalidade com o Criador. Abraão desperta mediante a essência administrativa, e sua práxis é a de ser o administrador e cocriador, pai de uma grande nação. "Na criação, pois, se encontra primeiramente uma revelação da vontade de Deus. Seu objetivo e seu fim, porém, é a revelação escatológica do ser de Deus na glória" (MOLTMANN, 1993, p. 128).

Nesse sentido, é possível afirmar que, nem mesmo a obra de Deus que está completa, é acabada. Dela participa o humano como agente ativo na edificação do reino, "é por isso que a criação tem um início, mas sua plenitude na glória de Deus não tem fim. Nesse sentido, Deus não é o 'Deus eterno-criador', mas sim o Deus que, no tempo e na eternidade, vai se tornando glorioso" (MOLTMANN, 1993, p. 129). 
Deus possibilita sustento e esperança à vida com e através das vidas humanas. Cada pessoa nesse processo é um oferecer-se ao Ser, na busca da plenitude, enquanto, vida humana até que "Deus seja tudo em todos" (1Corintios 15,28). É preciso quebrar o deus de barro/terra, possibilitar-se amar para além das paredes que envolvem a parentalidade, para "a fé posse antecipada daquilo que se esperança" (HB 11,1-3), o reino de Deus.

A morte propulsa o ser humano a ter menos e amar mais, vida e morte nos impulsionam ao movimento de eternidade na existência, propulsando o ciclo vital de fé, esperança, e caridade, sobre a qual se edifica o reino, assim, "O cristão tem o dever de participar, também ele, nessa a busca diligente, na organização e na vida da sociedade política" ( $\left.\mathrm{OA}^{5} 24\right)$. Ser cocriador e administrador é reconhecer-se filho de Deus, a serviço do próximo e na edificação da obra de Deus.

\section{Os dons de pessoa no espírito criador}

Sob o intuito de relação, diante da vivência humana é possível enfatizar que o amor se prolifera à dimensão de sociabilidade humana, isto é, há cuidados para com o próximo que superam a própria conjugalidade e unidualidade do casal, e assim se possibilita dar continuidade à vida humana. É em comunhão que se possibilita o diálogo refletido no outro; é também dessa comunhão que se possibilita a vida e assim se fazem cônjuges, pai, mãe, filhos e toda a parentalidade.

A importância de uma educação para a vida em sociedade, em que, para além da informação sobre os direitos de cada um, seja recordado também o seu necessário correlativo: o reconhecimento dos deveres de cada um em relação aos outros. (OA 24).

Sob esse ambiente de alteridade, de responsabilidade e de contingência faz-se a cumplicidade que propicia acreditar e confiar no outro, fazendo de cada pessoa uma história de participação na sociabilidade humana. Sobre o preceito de uma liberdade social, torna-se enfática a capacidade humana em ouvir a própria voz, porque a condição primeira do amor é o livre-arbítrio é ter a capacidade de amar.

A possibilidade de falar face a face se faz diante da capacidade de reconhecerem-se criaturas, carne da mesma carne e ossos dos mesmos ossos, e de ter a oportunidade de dar continuidade ao ato amoroso e criador de Deus. Somos feitos do búmus da terra, todavia capazes da essência administrativa

PAULO VI, Octagesima Adveniens, 1971. 
e, por isso, participantes do Espírito cocriador e administrador da obra de Deus, Templos do Espírito, "É necessário voltar a considerar a família como o santuário da vida" (CA $\left.{ }^{6} 39\right)$.

São importantes os cuidados e ensinamentos na perspectiva de que os núcleos de parentalidade se expressem enquanto exemplos de viver o amor. É preciso, em primeiro lugar, zelar e perceber que se transmite a vida, e não os genes da morte; cada filho que nasce é a vida que continua lutando contra a morte e o pecado. Permitir e compreender a dignidade da pessoa é tarefa humana, tornando-se um correspondente em esponsalidade, porque “a 'natureza' da pessoa é sua 'relação' com Deus. Na relação, a pessoa fica sendo sempre pessoa" (MOLTMANN, 1993, p. 321):

Ser social, o homem, constrói o seu destino numa série de grupos particulares que exigem, como seu complemento e como condição necessária para o próprio desenvolvimento, uma sociedade mais ampla, de características universais, a sociedade política. (OA 24).

Relação com o Criador - aqui compreendida como esponsalidade -, possibilita o ser humano a ser cocriador e administrador dos mistérios de Deus. A essência administrativa é práxis e, por isso, o agir humano é "condicionados pelo domínio de si mesmo, pela aceitação das responsabilidades e das limitações impostas ao exercício da liberdade do indivíduo ou do grupo" (OA 24).

No minuto de solidão, aquele que se opõe a Deus, pergunta a Eva sobre seu modo de viver, e é perceptível que 'Eva' sabe o que é possibilitado e o que não é possibilitado, mas a voz, 'a própria voz', é contundente e diz: Não, não é bem assim:

"Sereis como Deus" (Gênesis 3,5). Eles quiseram ter o domínio absoluto sobre todas as coisas, sem se submeterem à vontade do Criador. Desde então o solo se torna avaro, ingrato, surdamente hostil (cf. Gn 4,12); somente com o suor da fronte será possível extrair dele alimento (cf. Gênesis 3,17.19). ( $\left.\mathrm{CDSI}^{7} 256\right)$.

A expressão "eles quiseram ter o domínio absoluto" (CDSI 256) é interessante, porque remete ao humano e, na verdade, a 'voz sedutora' é a própria voz, que se contrapõe à voz que direciona ao Bom, ao Belo, e ao Verdadeiro, uma voz que é a essência administrativa e que habita o íntimo humano e é capaz de esponsalidade com o Criador.

\footnotetext{
JOÃO PAULO II, Centesimus annus, 1991.

JOÃO PAULO II, Compêndio da Doutrina Social da Igreja.,2004.
} 
Cada filho precisa compreender sua razão de viver, e é esta a grande função da parentalidade enquanto administradores e cocriadores, revelar ao humano sua humanidade diante da esponsalidade. Nesse sentido, a parentalidade, enquanto reflexo do amor de Deus, "é o lugar onde a vida, dom de Deus, pode ser convenientemente acolhida e protegida contra os múltiplos ataques a que está exposta, e pode desenvolver-se segundo as exigências de um crescimento humano autêntico" (CA 39).

O Criador não quer dominar o espaço dado ao humano, por isso o faz portador, mas não submisso à essência administrativa, o convida a um processo onde se faz a economia da salvação, "Contra a denominada cultura da morte, a família constitui a sede da cultura da vida" (CA 39). É preciso se direcionar aos valores do reino, da nação dos filhos de Deus, nação sem os limites geográficos, mas as nações dos que agem segundo o amor de Deus.

\section{O agir humano enquanto fonte de amor}

É enfático que Cristo, não transforma o humano em Deus ou Deus no humano, mas que Cristo revela que fazendo a vontade do Criador, segundo os dons de cada pessoa, mantém-se ungido e em esponsalidade. Em esponsalidade o ser humano eleva-se à essência administrativa, na práxis de cocriar e administrar a obra de Deus por meio da economicidade, da sociabilidade e da parentalidade.

A parentalidade é unidade primeira da família humana, por isso local onde nasce o amor, como fonte que jorra sem cessar, é a parentalidade que em sociabilidade edifica a economicidade que propicia a cada pessoa desenvolver-se e sentir a presença do Reino que já se faz presente. Quando se enfatiza a parentalidade se pontua que se pensa nos laços consanguíneos e também nas diversas relações que, mesmo que não haja os laços consanguíneos, envolvem as pessoas à pertença parental.

A parentalidade é local, onde por amor, desenvolve a economicidade que possibilita, por intermédio dos esforços de cada pessoa apta e segundo seus dons, sustentar a obra de Deus, " $A$ luz da Revelação, a atividade econômica deve ser considerada e desenvolvida como resposta reconhecida à vocação que Deus reserva a cada homem" (CDSI 326).

Há no humano um Si de Deus - a essência administrativa -, fazendo com que as pessoas aptas ao trabalho produzam mais que o necessário para si e colocam como sustento, pão da vida, para as pessoas não aptas ao trabalho. Em se tratando do ser humano, é possível enfatizar que "Ele é colocado no Jardim para cultivá-lo e guardá-lo, usando-o dentro de limites bem precisos 
(cf. Gênesis 2,16-17), no esforço de aperfeiçoamento (cf. Gênesis 1,26-30; 2,1516; Sab 9,2-3)" (CDSI 326).

O ser humano, não pode desvincular-se de sua própria necessidade e, neste sentido, está à exigência de alteridade ao próximo; o trabalho revela algo de si à criação de Deus, e o humano é, então, o ato administrativo e cocriador de Deus na criação em desenvolvimento. É preciso reorientar-se, de modo que cada pessoa possa perceber que, tão importante quanto a quantidade de postos de trabalho, é a qualidade desse trabalho, e o que esse trabalho desenvolve no humano que o executa.

É possível que se fale que a ausência de postos de trabalho está associada ao limite de horas de trabalho. Quando não se tem horas de trabalho a cumprir, mas tarefas a serem executadas, se desfaz a ausência de postos de trabalho. Constitui-se a lógica das necessidades, das possibilidades, e dos subsídios, este é um chamado a administrar a obra de Deus, com isso a essência administrativa, propulsa a práxis, onde,

Uma boa administração dos dons recebidos, também dos dons materiais, é obra de justiça para consigo mesmo e para com os outros homens: aquilo que se recebe deve ser bem utilizado, conservado, acrescido, tal como ensina a parábola dos talentos (cf. Mt 25,14-31; Lc 19,12-27). (CDSI 326).

É preciso da Graça, e por isso, aquilo que o humano faz, precisa ter a sutileza do Ser, do contribuir para a família humana, de modo que os fins não justificam os meios. Sob o atributo de pessoalidade, as sociedades e as grandes empresas, reorientam-se e, neste sentido: "torna-se urgente reconstituir, em nível de rua, de bairro, ou de aglomerado ainda maior, aquela rede social em que o homem possa satisfazer as necessidades da sua personalidade" (OA 11).

É preciso exercitar-se como administradores e cocriadores no reino de Deus, cada pessoa, segundo seus dons, contribui para o fortalecimento da sociedade, edificando a consciência e subsidiando as pessoas, para que possam ser livres, isto é, terem a capacidade de fazer e se responsabilizar pelo que fazem, e assim é que,

Devem ser criados centros de interesse e de cultura, ou desenvolvidos se já existem, ao nível das comunidades e das paróquias, naquelas diversas formas de associação, naqueles círculos de recreação, naqueles lugares de reunião, naqueles encontros espirituais comunitários, etc., em que cada um possa sair do isolamento e tornar a criar relações fraternas. (OA 11).

O sentido de retorno que existe no humano, é inerente à sua esponsalidade com o Criador; se um trabalho não permite o tempo necessário de 
estar junto à família, não pode ser considerado economicidade humana. O trabalho é para o ser humano e não o ser humano para o trabalho, a práxis de vida humana, envolve muito mais que horas de trabalho em uma empresa. O trabalho é apenas uma parte da atividade humana, enquanto administradores do reino de Deus.

A práxis humana envolve desenvolvimento da obra de Deus, o amor, e o trabalho é sempre um movimento de todas as pessoas em direção ao reino. No entanto, quando a atividade humana nega o reino, o que era para ser trabalho se torna fadiga. A alegria de administrar o cocriar o reino de Deus eleva a pessoa a agir segundo a vontade de Deus; ele se percebe ser humano, enquanto um ser à imagem e semelhança de Deus.

\section{O agir da pessoa reflete a semelhança de Deus}

Quando o ser humano pensa em explorar predatoriamente a natureza, em busca riquezas, destrói a economicidade, a sociabilidade e a parentalidade - o indivíduo chega ao ponto que "a avareza pessoal, familiar e nacional, pode afetar tanto os mais desprovidos como os mais ricos e suscitar em uns e outros um materialismo que sufoca o espírito" ( $\left.\mathrm{PP}^{8} 18\right)$. O trabalho contribui para saciar a fome, edifica o ser, e é fonte de alteridade que se realiza na ação de promover a vida humana, por isso, "O trabalho não deve afligir (cf. Mateus 6,25.31.34)" (CDSI 260).

O trabalho é o ato livre que resplandece da Graça de Deus, na edificação de seu projeto; assim, o trabalho não está unicamente para a atividade geradora de renda, mas para a economicidade humana. Ao viver "preocupado e agitado por muitas coisas, o homem corre o risco de negligenciar o Reino de Deus e a Sua justiça (cf. Mateus 6,33), de que verdadeiramente necessita" (CDSI 260).

Nesse ponto, é possível ao humano perceber as diferenças entre o ter e o ser no mundo, pois o ter move-se por um economicismo, uma exploração predatória que só enxerga a letra da Lei, mas torna o indivíduo cego para o exercício do mandado e do chamado de Deus, a cultivar e guardar a casa comum que dá sustento à vida humana,

Mas não faltam motivos de inquietação. Não poucos homens, com efeito, sobretudo nos países economicamente desenvolvidos, parecem dominados pela realidade econômica; toda a sua vida está penetrada por um certo espírito economístico tanto nas nações favoráveis à economia coletiva como nas outras. $\left(G S^{9} 63\right)$.

\footnotetext{
PAULO VI, Populorum Progressio, 1967.

PAULO VI, Gaudium et Spes, 1965.
} 
O humano é a razão necessária para o ordenamento e desenvolvimento da Criação, é por haver um reino em desenvolvimento que o ser humano é chamado/mandado a ser imagem e semelhança de Deus na Criação. $\mathrm{O}$ humano é criado do búmus da terra e da própria 'presença' de Deus, para ser o ato administrativo de Deus no mundo, a essência administrativa possibilita os Dons de cada pessoa, e com isso fomenta o Reino.

Se uma comunidade se movimenta de forma a corroborar uma estrutura produtiva, esta deve servi-la, e não escravizar as pessoas, explorando predatoriamente à obra de Deus. Aqui se observa a palavra trabalho, não apenas como esforço físico e/ou mental, mas, no sentido de economicidade em relação à pessoa livre, responsável e esclarecida.

Enfatiza-se que nenhuma pessoa, apta ao trabalho, deve se privar ou ser privada dele, nem mesmo por ser o dono/proprietário/acionista. Essa fundamentação ganha respaldo no agir da pessoa que conhece as pessoas e suas fadigas. Toda pessoa é um ser em desenvolvimento, e enquanto processo a ser desenvolvido, precisa edificar-se enquanto homo ad-minister, isso é, no esforço físico e/ou mental na práxis de um ser que administra e cocria, mas é por estar em esponsalidade que o esforço, humano, será sempre aquilo que antecede a atitude, práxis do referido esforço.

O deslocamento da família humana na edificação do reino, a um papel secundário, relativiza a economicidade e sua abrangência, por fim se põe a construir ideologias e abstrações da realidade que vão, aos poucos, esvaziando o sentido do existir da própria humanidade. A capacidade com a qual o humano, zela pela segurança, pelo alimento, moradia, saúde, não pode reduzir-se à fadiga do esforço físico e/ou mental. Para Sanches (2007, p. 152), "estamos aqui diante da problemática da existência humana e do agir humano, entre a liberdade e a dependência, liberdade para agir, e dependência de Deus para agir corretamente".

Por isso, sempre que se alude ao trabalho, não se deve trazer à baila simplesmente o fato de alguém que tem um emprego, mas ao conjunto de atividades que uma pessoa desenvolve em esponsalidade, ou seja, uma autêntica atividade econômica.

\section{O Cristo e a criatura ungida}

Quando se reduz a economicidade da pessoa, ao esforço físico e/ou mental, detêm-se à fadiga do trabalho para o suprimento das necessidades individuais. Todavia, "O trabalho não deve afligir (cf. Mateus 6, 25.31.34)" (CDSI 260). Há, entre a Graça e a Providência Divina, a essência administrativa, que é plenificada mediante a esponsalidade do ser humano com o Criador. 
Quando o esforço físico e mental se faz em dimensão de economicidade, é fator de desenvolvimento, progresso participativo e compartilhado. Sanches (2007, p. 152) enfatiza que, "sem Deus a liberdade humana se absolutiza, se torna um valor em si mesmo, e a ação que nasce de tal liberdade é confusa, se justifica por si só, não tem direção, nem coerência”.

A economia "é apenas um aspecto e uma dimensão da complexa atividade humana. Se ela for absolutizada, se a produção e o consumo das coisas acabar por ocupar o centro da vida social, tornando-se o único valor verdadeiro da sociedade, não subordinado a nenhum outro, a causa terá de ser procurada não tanto no próprio sistema econômico, quanto no fato de que todo o sistema sócio-cultural, ignorando a dimensão ética e religiosa, ficou debilitado, limitando-se apenas à produção dos bens e dos serviços”. (CDSI 375).

O caminhar deve acontecer em esponsalidade com Criador, por isso, Paulo VI (1971) enfatiza que a cidade é, por muitas vezes, apresentada "como sendo de fato o lugar do pecado e do orgulho; orgulho de um homem que se sente bastante seguro de si, para construir sem Deus a sua vida, e, mesmo, para se armar, com altivez contra Ele" (OA 12).

A sociabilidade possibilita às pessoas viverem em comunhão; formam-se, então, lugares de vivência e de convivência e, assim, constituem-se as comunidades, as cidades, os estados e as nações, "Aí vem também Jerusalém, a cidade santa, o lugar de encontro com Deus e a prefiguração da cidade que vem do alto" (OA 12). Desenvolve-se a cidade dos filhos de Deus, uma cidade/nação sem os limites geográficos, uma cidade edificada sobre a relação de amor.

A cultura que desenvolve o ambiente de convívio precisa estar aberta ao próximo, da mesma forma que estava aberta às pessoas que se uniram para formar esse local de convívio e, por isso, toda cidade/Estado deve ser "o lugar de encontro com Deus" (OA 12). Constrói-se pelas mãos humanas, sob as coisas possibilitadas por Deus, a cidade na qual se deseja estar com Deus, realizando-se no respeito ao chamado/mandado Ser cocriador e administrador.

O ser humano é, no Reino do Criador, a criatura ungida, que participa da vida divina, administrando e cocriando; é por isso que há a expressão de que buscar a Deus está para fazer a Sua vontade. Chega-se ao ponto em que, diante da soberba, da avareza e da possessividade implica afirmar que "O único fim que conta, é a busca do próprio bem-estar material" (EV 23).

É diante do familismo ${ }^{10}$, do individualismo, da ganância, que a vida humana se torna vazia, e diante da solidão original - o ser humano sem Deus -

10 Com a palavra familismo, se deseja pontuar o exclusivismo parental, que consiste em ver só os membros da parentalidade como pessoas aptas a receberem os devidos cuidados necessários a edificação da vida humana. O problema não é a parentalidade, mas sim, o desejo de fazer do mundo uma ideologia do familismo, uma defesa irrestrita dos parentes de forma a negligenciar os não parentes. 
e o único fim que resta e que a “'qualidade de vida' é interpretada prevalente ou exclusivamente como eficiência econômica, consumismo desenfreado, beleza e prazer da vida física, esquecendo as dimensões mais profundas da existência" (EV 23). O problema não é a parentalidade, mas sim o desejo de fazer do mundo uma ideologia do familismo, uma defesa irrestrita dos parentes de forma a negligenciar os não parentes.

Se o ser humano é um ser social, pode-se afirmar que, sem sociabilidade, o humano se dissocia de seu próprio ser. Somos em sociabilidade, quando se predispõe em ser cônjuge, e a zelar pela família humana. No projeto de parentalidade, se dá continuidade à vida, todavia, surge a indagação:

O aparecimento de uma civilização urbana, que acompanha o incremento da civilização industrial, não será, na realidade, um verdadeiro desafio lançado à sabedoria do homem, à sua capacidade de organização e à sua imaginação prospectiva? (OA 10).

Esses desafios lançados sobre a sabedoria humana, tornam-se para as pessoas em esponsalidade, o despertar à essência administrativa. Todavia quando obscurecidos, muitos lançam mão da família humana, fomentando a assertiva, da verdade de cada um, constituindo o bem comum "o conjunto de condições da vida social que permitem, tanto aos grupos, como a cada um dos seus membros, atingirem mais plena e facilmente a própria perfeição" (CDSI 164).

O problema não é a família, mas o desejo de dominar o mundo usando a família - familismo, o desejo que rege uma família é o de liberdade, livre-arbítrio, respeito, partilha e responsabilidade pela obra de Deus. E nesse sonho de família humana, que deve estar toda pessoa, e não apenas os filhos/parentalidade.

\section{A exploração predatória em função da parentalidade}

Quando se faz da parentalidade, um local em que é preciso viver pela submissão, os cônjuges se afastam da esponsalidade, porque o efeito de ser o submissor torna-o tão submisso quanto quem vive em submissão. O submissor é dependente da soberba e do poder, isso não é o Reino de Deus. Quando a soberba e a avareza prevalecem no individuo, a parentalidade se torna a justificativa de exploração e acumulação predatória.

Quando pervertidas da vontade de Deus, as pessoas precisam, a qualquer custo, garantir o enriquecimento, a posse, e o poder, sob o preceito de ser esposo, esposa, e se ter filhos. É preciso, então, abastar-se das coisas, características essas de um ser avarento e soberbo. 
A essência administrativa possibilita a práxis de compreender as necessidades, as possibilidades, e os subsídios, para que se possa dar continuidade à vida humana. A história escrita pelas mãos de cada pessoa, deve conter a alteridade, que torna prospera a vivência humana na contingência do reino, Paulo VI (1971) preconiza que,

Se, efetivamente, para além das regras jurídicas, falta um sentido profundo do serviço de outrem, mesmo a legalidade perante a lei poderá servir de álibi para flagrantes discriminações, para se manterem explorações e para um desprezo efetivo. (OA 23).

A parentalidade não se resume ao conhecimento, ao modelo de 'divindade', mas a dois seres de sexo complementar, que decidem por viver toda dinâmica de uma união, e não se adaptarem a um modelo, neste sentido se não houver uma "renovada educação, no que se refere à solidariedade, uma excessiva afirmação da igualdade pode dar azo a um individualismo em que cada qual reivindica os seus direitos, sem querer ser responsável pelo bem comum" (OA 23).

Porque é "o amor do homem, primeiro valor da ordem terrestre" (OA 23), por isso, frisa-se que, o que torna os cônjuges um sacramento, não é o fato de se unirem diante de um rito, mesmo porque, a sacramentalização não imprime caráter. Mas, o fato de que o casal possa pôr-se em matrimônio e patrimônio a serviço dos filhos de Deus.

Por vezes, compreende-se o sacramento do matrimônio como uma 'coisa' dispersa da vida dos cônjuges, João Paulo II (1987) fomenta o amor e que, para "alcançar o verdadeiro desenvolvimento é necessário não perder jamais de vista esse parâmetro, que está na natureza específica do homem, criado por Deus à sua imagem e semelhança (cf. Gênesis 1,26)" (SS $\left.{ }^{11} 29\right)$.

A essência administrativa - um Si de Deus -, soprado ao íntimo humano, possibilita compreender as necessidades, as possibilidades e os subsídios. Sem a essência administrativa, o humano torna-se avarento, endeusa-se, e começa a comportar-se como possuidor de privilégios, o eleito por "deus" para viver bem, com base no sacrifício de quem "deus" escolheu para sofrer.

$\mathrm{Na}$ absolutização de si, o ser humano deixa de ser um mordomo/ administrador na obra de Deus, e coloca 'deus' a seu serviço, momento no qual 'deus' se torna o mordomo e administra o mundo para suprir o ser avarento, idolátrico e egolátrico. Triste estágio da humanidade, o indivíduo para se valer dos aspectos econômicos, faz com que a satisfação das possibilidades de alguns cause necessidades de outros. Não se podem tornar os

11 JOÃO PAULO II, Sollicitudo rei socialis, 1987. 
subsídios para a vida em prazer de alguns e dores para outros, ignorando a humanidade no humano.

O esforço humano não pode concentrar-se na geração de riquezas, cifras monetárias, mas permitir a ele agir na perspectiva do Reino, de modo que "a dignidade do trabalho aparece definido como 'a atividade humana destinada a prover ás necessidades da vida e, especialmente, à sua conservação"' (CA 6). A idolatria absolutiza a 'coisa'; todavia, é preciso notar que não é a coisa idolatrada que passa a fazer parte do indivíduo, é o próprio indivíduo que se insere na coisa idolatrada.

Ao estar totalmente idólatra, o ser humano chega ao ponto que a falta da coisa possuída provoca dores e desequilíbrios na estrutura biológica e psicológica do idólatra, até que se tenha a idolatria de ser egolátrico. É necessário desenvolver a noção de ser família humana, uma vez que Pio XI (1931) preconiza que, "de qualquer modo que seja distribuída entre os particulares, não cessa a terra de servir à utilidade pública” (QA $\left.{ }^{12} \mathrm{II}, 1\right)$.

\section{Considerações finais}

O ser humano, criado à imagem e semelhança de Deus é, por isso, chamado/mandado a exercer o domínio sobre a criação, todavia, o amor só existe onde há o livre-arbítrio, neste sentido, e diante da contingência do reino se é apresentado ao dom de administrar. O domínio humano sobre a criação deve ser exercido, segundo a vontade do Criador e, assim, o ser humano recebe de Deus o Dom dos Dons, a Essência Administrativa, o si de Deus que habita o íntimo de cada pessoa.

Os dons de cada pessoa são exercidos no Espírito Criador, isso implica dizer que a essência administrativa é resultante da esponsalidade com o Criador. A egolatria é o afastar-se do projeto de Deus, para viver o próprio projeto, assim se destrói o projeto de Deus, ao se negar o próprio jeito de Deus reinar. O jeito de Deus cuidar, se faz mediante o agir de cada pessoa que deve refletir a atitude de cada pessoa à imagem e semelhança de Deus, ou seja, o reinar/administrar humano deve ser ao modo como Deus cuida de cada pessoa, é um agir em perspectiva do Reino.

Quando o agir humano reflete a semelhança do agir/reinar de Deus, a pessoa é, então, a criatura ungida que Deus criou para administrar o reino, neste sentido, Jesus, o Cristo, não ensina o ser humano a ser Deus, mas, a ser criatura ungida, que ama e ensina a amar, que compreende o reino de Deus e proclama o reino de Deus a quem se sente excluído. Diante destes

12 PIO XI, Quadragesimo anno, 1931. 
elementos, se faz perceber um reino, um jeito de reinar/administrar que apresenta e desenvolve em perspectiva do futuro, onde toda pessoa é rei/ administrator, sacerdote e profeta.

A criatura ungida, administra a obra de Deus, tendo por base as dimensões de sociabilidade, de parentalidade e de economicidade, quando o ser humano se porta a explorar predatoriamente a criação para suprir de 'riquezas' a própria parentalidade, se comporta como um tirano e não consegue compreender o projeto de Deus. O ser humano, diante do familismo, explora o próximo/outro para construir o próprio projeto parental, se afastando do projeto de amor e desenvolvimento do Reino.

Quando se explora predatoriamente a criação e, nesta o próprio ser humano, se impossibilita o próprio livre-arbítrio, por fim, o indivíduo se torna idolátrico e egolátrico se afastando da esponsalidade com o Criador, torna-se incapaz da essência administrativa, já não age como um administrador da obra de Deus, mas como o destruidor, demolidor. Neste sentido, o ser humano, que era para exercer o cuidado da Terra/Criação, se torna aquele que demoniza a obra de Deus.

\section{Referências bibliográficas}

BÍBLIA. Bíblia de Jerusalém. Nova ed. revisada e ampliada. São Paulo: Paulus, 2012.

BRUNER, Jerome. Atos de significação. 2. ed. Trad. Sandra Costa. São Paulo: Artmed, 2002. CLANDININ, D. Jean; CONELLY, F. Michael. Pesquisa narrativa: experiências e história na pesquisa qualitativa. Trad. Grupo de Pesquisa Narrativa e Educação de Professores ILEEL/UFU. Uberlândia: EDUFU, 2011.

FRANCISCO. Laudato Si'. Roma: Libreria Editrice Vaticana, 2015. Disponível em: http:// w2.vatican.va/content/francesco/pt/encyclicals/documents/papa-francesco_20150524_enciclica-laudato-si.html [Acesso em: 29 set. 2017].

JOÃO PAULO II. Centesimus annus. Roma: Libreria Editrice Vaticana, 1991. Disponível em: <http://w2.vatican.va/content/john-paul-ii/pt/encyclicals/documents/hf_jp-ii_ enc_01051991_centesimus-annus.html> [Acesso em: 29 set. 2017].

JOÃO PAULO II. Compêndio da Doutrina Social da Igreja. Roma: Libreria Editrice Vaticana, 2004. Disponível em: <http://www.vatican.va/roman_curia/pontifical_councils/justpeace/ documents/rc_pc_justpeace_doc_20060526_compendio-dott-soc_po.html> [Acesso em: 29 set. 2017].

JOÃO PAULO II. Evangelium vitae. Roma: Libreria Editrice Vaticana, 1995. Disponível em: <http://w2.vatican.va/content/paul-vi/pt/encyclicals/documents/hf_p-vi_enc_25071968_ humanae-vitae.html> [Acesso em: 29 set. 2017].

JOÃO PAULO II. Sollicitudo rei socialis. Roma: Libreria Editrice Vaticana, 1987. Disponível em: <http://w2.vatican.va/content/john-paul-ii/pt/encyclicals/documents/hf_jp-ii_enc_30121987_sollicitudo-rei-socialis.html> [Acesso em: 29 set. 2017]. 
MOLTIMANN, Jürgen. Deus na criação: doutrina ecológica da criação. Trad. Haroldo Reimer e Ivoni Richter Reimer. Petrópolis: Vozes, 1993.

PAULO VI. Gaudium et Spes. Roma: Libreria Editrice Vaticana, 1965. Disponível em: <http://www.vatican.va/archive/hist_councils/ii_vatican_council/documents/vat-ii_ const_19651207_gaudium-et-spes_po.html> [Acesso em: 29 set. 2017].

PAULO VI. Octagesima Adveniens. Roma: Libreria Editrice Vaticana, 1971. Disponível em: <http://w2.vatican.va/content/paul-vi/pt/apost_letters/documents/hf_p-vi_ apl_19710514_octogesima-adveniens.html> [Acesso em: 29 set. 2017].

PAULO VI. Populorum Progressio. Roma: Libreria Editrice Vaticana, 1967. Disponível em: <http://w2.vatican.va/content/paul-vi/pt/encyclicals/documents/hf_p-vi_enc_26031967_ populorum.html> [Acesso em: 29 set. 2017].

PIO XI. Quadragesimo anno. Roma: Libreria Editrice Vaticana, 1931. Disponível em: $<$ https://w2.vatican.va/content/pius-xi/pt/encyclicals/documents/hf_p-xi_enc_19310515_ quadragesimo-anno.html> [Acesso em: 29 set. 2017].

SANCHES, Mário Antônio. Brincando de Deus: bioética e as marcas sociais da genética. São Paulo: Ave Maria, 2007.

Submetido em: 28-5-2020

Aceito em: 15-10-2020 